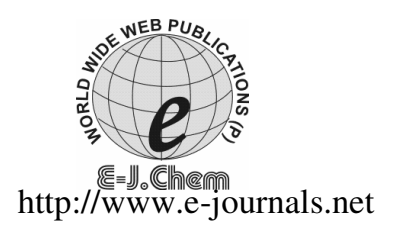

ISSN: 0973-4945; CODEN ECJHAO

E-Journal of Chemistry

2010, 7(4), 1274-1277

\title{
Assessment of Water Quality Parameters by Using the Multidimensional Scaling Analysis
}

\author{
SUHEYLA YEREL ${ }^{*}$ and HUSEYIN ANKARA \\ *Bilecik University, Civil Engineering Department, Bilecik, Turkey. \\ Eskisehir Osmangazi University, \\ Mining Engineering Department, Eskisehir, Turkey. \\ suheyla.yerel@bilecik.edu.tr
}

Received 12 January 2010; Accepted 7 March 2010

\begin{abstract}
The surface water quality parameters of the western region of Black Sea in Turkey were assessed by using multidimensional scaling analysis. This technique was applied to the surface water quality parameters obtained from the five monitoring stations. Multidimensional scaling analysis showed that $\mathrm{Cl}^{-}$, $\mathrm{SO}_{4}{ }^{2-}, \mathrm{Na}^{+}$and $\mathrm{BOD}_{5}$ are the most important parameters causing difference in the monitoring stations. These analysis results present from the domestic waste and organic pollution affected of surface water quality. Thus, this study represents the usefulness of multidimensional scaling analysis for interpretation in the river pollution problems.
\end{abstract}

Keywords: Multidimensional scaling analysis, Western region of Black Sea, Water quality, Pollution.

\section{Introduction}

Surface water quality is affected by both anthropogenic activities and natural process. Natural processes influencing water quality include precipitation rate, weathering processes, and sediment transport, whereas anthropogenic activities include urban development and expansion and industrial and agricultural practice. These activities often result in the degradation of water quality, physical habitat, and biological integrity of river system ${ }^{1-2}$. Increasing exploitation of water resources in catchment is responsible for much of the pollution $\operatorname{load}^{3}$. On the other hand, rivers and streams play a major role in assimilation or carrying off the municipal and industrial waste-water and run-off from agricultural land ${ }^{4}$. In Turkey, the water quality problems have increased since 1970, due to rapid growth of industry, population concentration in large cities, transport and per capita use of water much more than before. The large volumes of wastes from domestic and industrial sources were initially discharged to the environment without treatment. From land and the atmosphere, the surface waters have been receiving the majority of these wastes ${ }^{5}$. 
Multidimensional scaling analysis is used to incorporate larger numbers of variables measured in surface water system. The application of these analysis, help in the interpretation of complex dataset, in order to allow a better understanding of the spatial variations in river water. Multidimensional scaling analysis permits identification of the possible sources that are responsible for the variations in water quality, influencing the water system and apportionment of the sources. Thus, this technique is valuable tools for developing appropriate strategies for effective management of the river water.

The aim of this study was to determine the most important variables causing difference in the water quality for the western region of Black Sea in Turkey by using the multidimensional scaling analysis.

\section{Experimental}

Surface water quality dataset of five water quality stations comparing six water quality parameters monitoring three years were obtained from the general directorate of state hydraulic works in Turkey. Coordinates of monitoring stations are seen in Table 1. The selected water quality parameters are; dissolved oxygen (DO), chloride $\left(\mathrm{Cl}^{-}\right)$, sulphate $\left(\mathrm{SO}_{4}{ }^{2-}\right)$, Phosphate $\left(\mathrm{PO}_{4}\right)$, sodium $\left(\mathrm{Na}^{+}\right)$and biochemical oxygen demand $\left(\mathrm{BOD}_{5}\right)$. All of the parameters were evaluated by using the multidimensional scaling analysis. All statistical computation was made using the statistical software.

Table 1. Surface water quality monitoring stations coordinate

\begin{tabular}{cccc}
\hline Station No & UTM Zone & UTM_X & UTM_Y \\
\hline S1 & 36 & 478,386 & $4,563,065$ \\
S2 & 36 & 461,401 & $4,375,400$ \\
S3 & 36 & 410,652 & $4,580,489$ \\
S4 & 36 & 456,155 & $4,476,560$ \\
S5 & 36 & 423,240 & $4,610,071$ \\
\hline
\end{tabular}

Multidimensional scaling analysis

A multidimensional scaling analysis is an appropriate exploratory technique for treating problems with such a need for exploration ${ }^{6}$. The input of the procedure is the proximity matrix of the objects under investigation. It contains the values of a quantitative measure of the pair wise dissimilarities between the objects. The output, however, is a spatial configuration of points in some preferably low-dimensional space. This is the so called final configuration of the multidimensional scaling analysis solution. The goal of the procedure is to represent the observed structure of the proximity matrix in terms of the interpoint distance in the final configuration as well as possible. While aiming to reproduce the original rank order of the proximities as close as possible, non-metric multidimensional scaling analysis iteratively rearranges the points at a fixed dimension of the space until a suitable goodness of fit measure is optimized. The stress function is commonly minimized in this analysis. The number of the dimensions of a correct multidimensional scaling analysis solution should be sufficient enough to reveal the hidden structure underlying the proximity data. The final step in the procedure is the interpretation of the meaningful dimensions of the multidimensional scaling analysis solution ${ }^{7-8}$.

\section{Results and Discussion}

The particular problem in the case of surface water quality monitoring is the complexity associated with analyzing the large number of measured parameters. In this study, the surface water quality parameters were analyzed by using the multidimensional scaling analysis to determinate dissimilarities between monitoring stations. 
Standardized residual sum of squares, used to assess how well a particular configuration reproduces the observed distance matrix, was found to be 0.01 even for the multidimensional scaling analysis. Standardized residual sum of squares values close to zero shows that the "fit" is almost perfect; and therefore, results of the multidimensional scaling analysis was reasonable and reliable ${ }^{9}$. The multidimensional scaling analysis coordinate values of the monitoring stations can be seen in Table 2 and Figure 1.

Table 2. Multidimensional scaling analysis coordinate values of the monitoring stations

\begin{tabular}{ccc}
\hline Stations & Dimension 1 & Dimension 2 \\
\hline S1 & 0.4240 & -0.1577 \\
S2 & -2.1756 & 0.5671 \\
S3 & -0.2188 & -1.3122 \\
S4 & 1.1719 & 0.9770 \\
S5 & 0.7984 & -0.0741 \\
\hline
\end{tabular}

The dissimilarities among the five monitoring stations were found according to Dimension-1 and Dimension-2. Figure 1 illustrates that the Station 2 (S2) and Station 4 (S4) are the most dissimilar monitoring stations according to the Dimension-1. Similarly, Station 3 (S3) and Station 4 (S4) are the least similar monitoring stations according to Dimension-2.

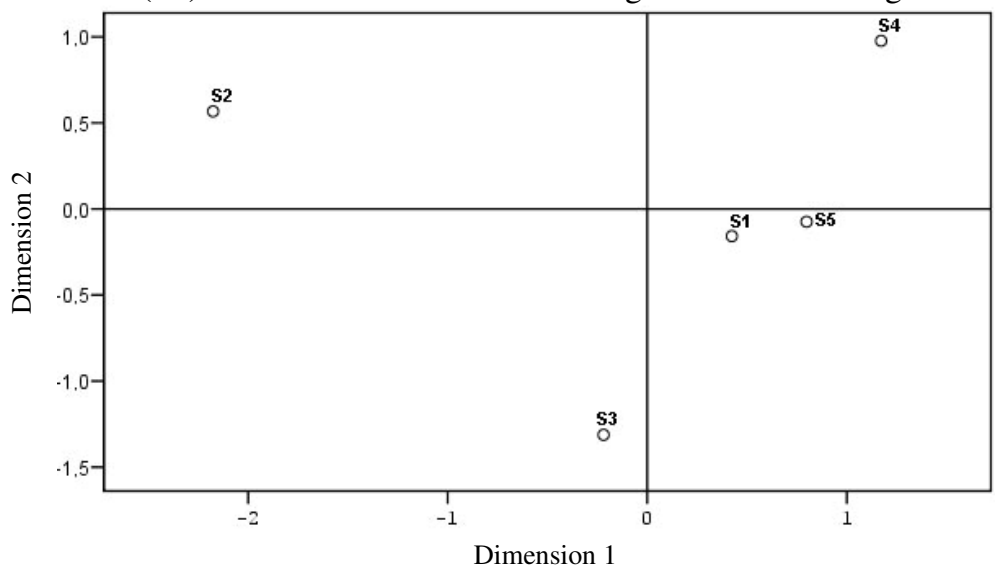

Figure 1. Multidimensional scaling analysis plot for the monitoring stations

The parameters causing dissimilarity between $\mathrm{S} 2$ and $\mathrm{S} 4$ can be seen from Figure 2. It is clear from the figure, $\mathrm{Cl}^{-}, \mathrm{SO}_{4}^{2-}, \mathrm{Na}^{+}$and $\mathrm{BOD}_{5}$ are the most important parameters causing this dissimilarity. These parameters represent from the domestic waste and organic pollution.

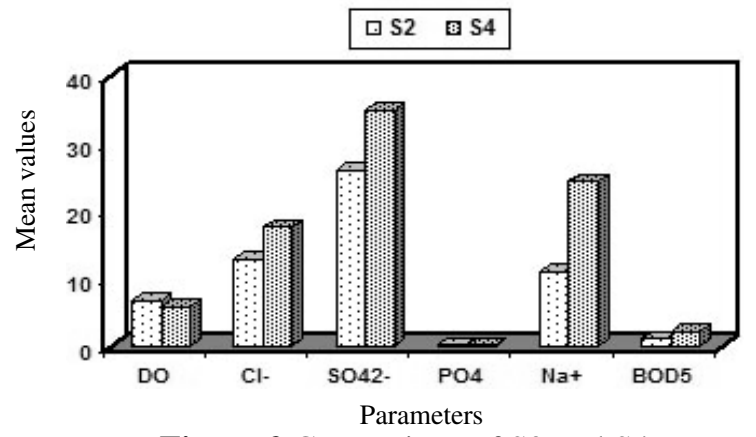

Figure 2 Comparison of S2 and S4 
The surface water quality parameters causing dissimilarity according to Dimension-2 can be seen from Figure 3. This figure shows that the $\mathrm{Cl}^{-}, \mathrm{SO}_{4}{ }^{2-}, \mathrm{Na}^{+}$and $\mathrm{BOD}_{5}$ causing differences between S3 and S4. Thus, Figures 3-4 was supported by the multidimensional scaling analysis.

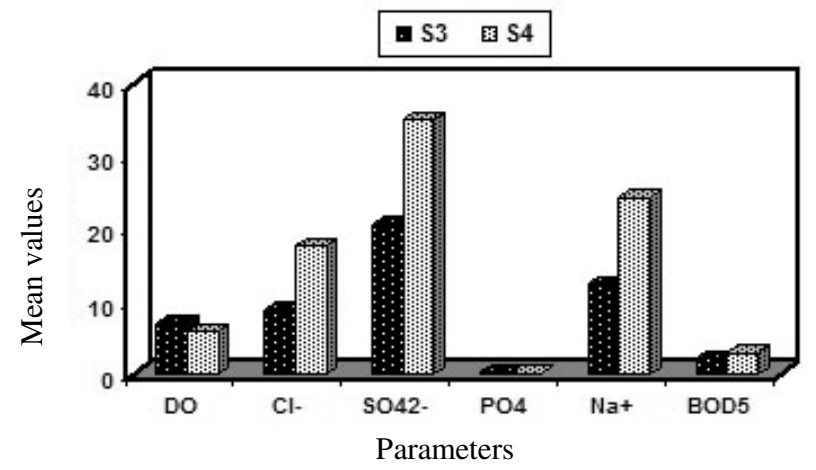

Figure 3. Comparison of $\mathrm{S} 3$ and $\mathrm{S} 4$

As was stated above, $\mathrm{Cl}^{-}, \mathrm{SO}_{4}{ }^{2-}, \mathrm{Na}^{+}$and $\mathrm{BOD}_{5}$ are the most important surface water quality parameters causing differences among the monitoring stations in western region of Black Sea in Turkey.

\section{Conclusion}

Multidimensional scaling analysis can be used successfully to acquire the relevant information from surface water quality parameters. The parameters, which were obtained from five monitoring stations at the western region of Black Sea in Turkey, were evaluated by using the multidimensional scaling analysis. Multidimensional scaling analysis was used to classify monitoring stations with dissimilarities in the western region of Black Sea in Turkey. According to Dimension 1 and Dimension 2 were found to be most important parameters causing differences in monitoring stations were $\mathrm{Cl}^{-}, \mathrm{SO}_{4}{ }^{2-}, \mathrm{Na}^{+}$and $\mathrm{BOD}_{5}$. Finally, this study shows that the usefulness of multidimensional scaling analysis in surface water quality parameters examination and determination of pollution sources.

\section{Acknowledgments}

The author sincerely thanks the General Directorate of State Hydraulic Works in Turkey for their help in providing the necessary data.

\section{References}

1 Carpenter S R, Caraco N F, Correll D L, Howarth R W, Sharpley A N and Smith VH, Ecol Appl., 1998, 83, 559-568.

2 Qadir A, Malik R N and Husain S Z, Environ Monit Assess., 2008, 140, 43-59.

3 Singh K P, Malik A and Sinha S, Anal Chim Acta., 2005, 538, 355-374.

$4 \quad$ Varol M and Sen B, Environ Monit Assess., 2009, 159, 543-553.

5 Morkoc E, Legovic T, Okay O S Tufekci H, Tufekci V Tolun L and Karakoc F T, Environ Geology, 2007, 53, 103-112.

6 Borg I and Groenen P, Modern multidimensional scaling theory and applications; Springer New York, 1996, 496.

7 Evtimov S and Ivanov M. Theoretical and Applied Climatology, 2007, 90, 161-168.

8 Yerel S, Asian J Chem., 2009, 21, 7234-7240.

9 Iscen C F, Altin A, Senoglu B and Yavuz H S, Environ Monit Assess., 2009, 151, 259-264. 


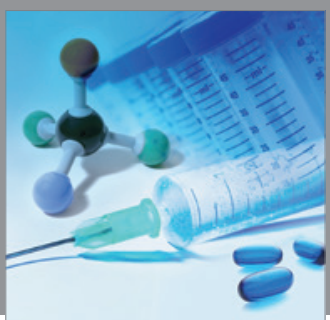

International Journal of

Medicinal Chemistry

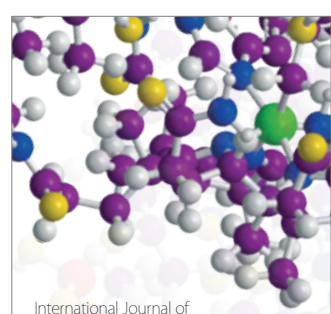

Carbohydrate Chemistry

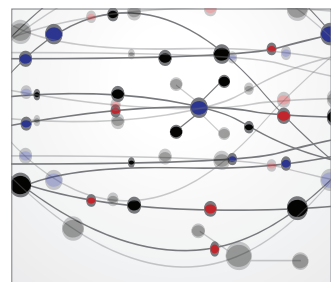

The Scientific World Journal
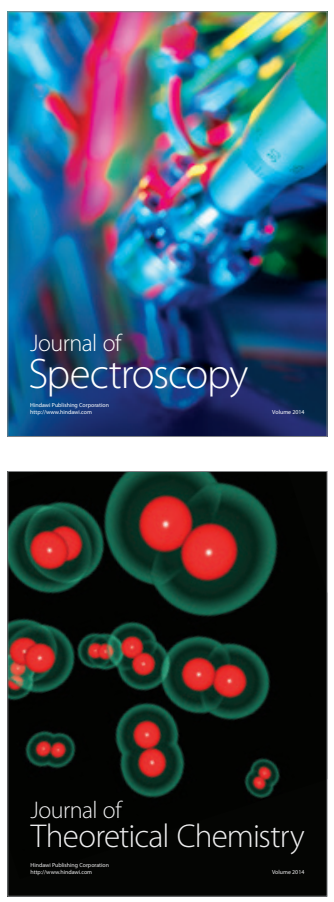
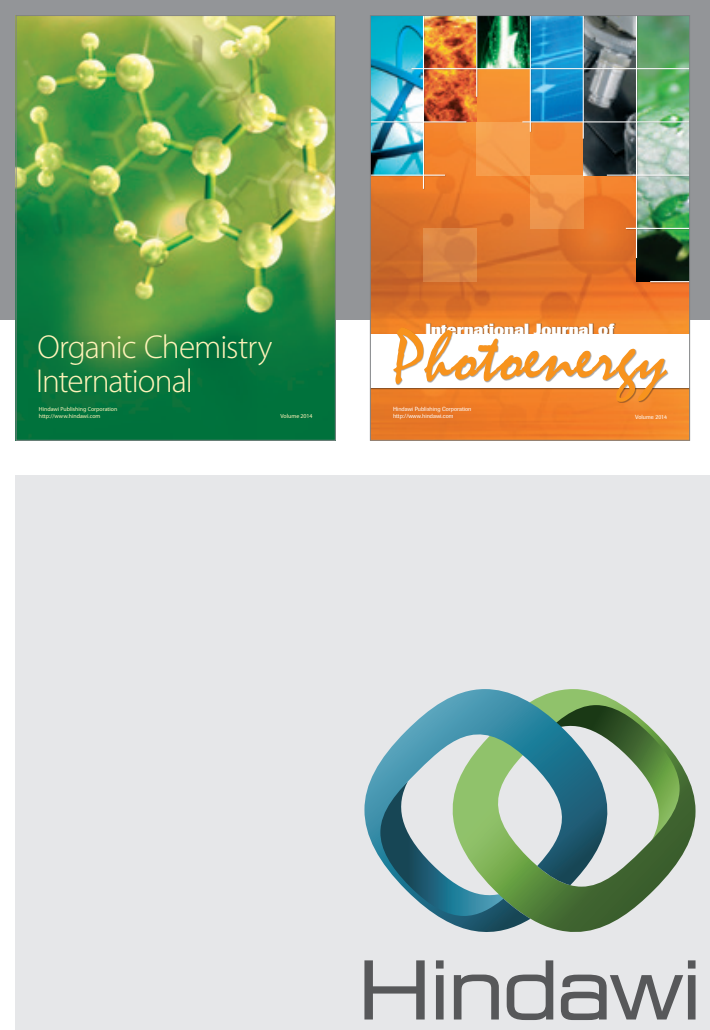

Submit your manuscripts at

http://www.hindawi.com
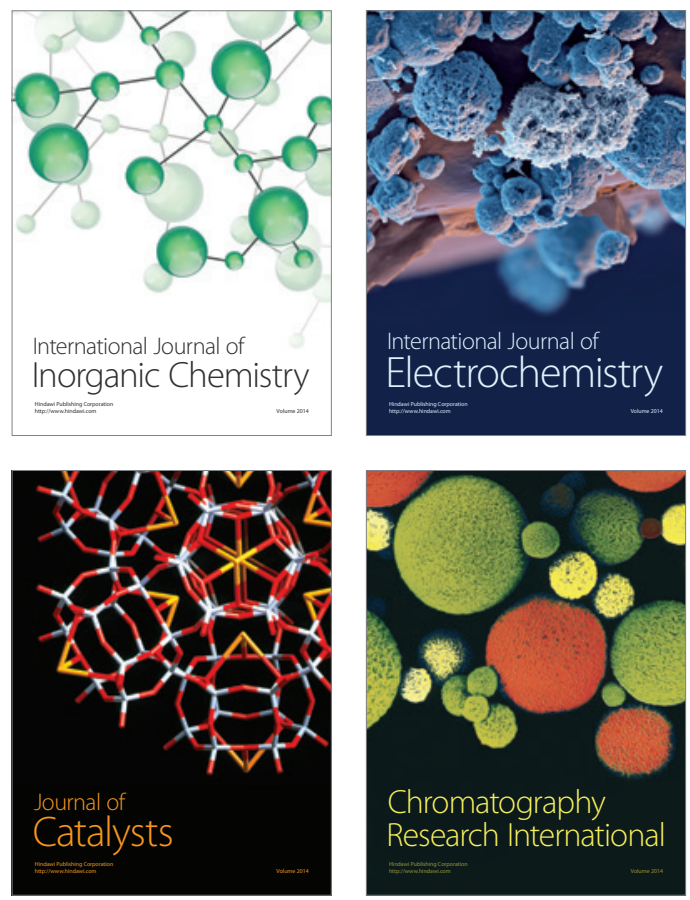
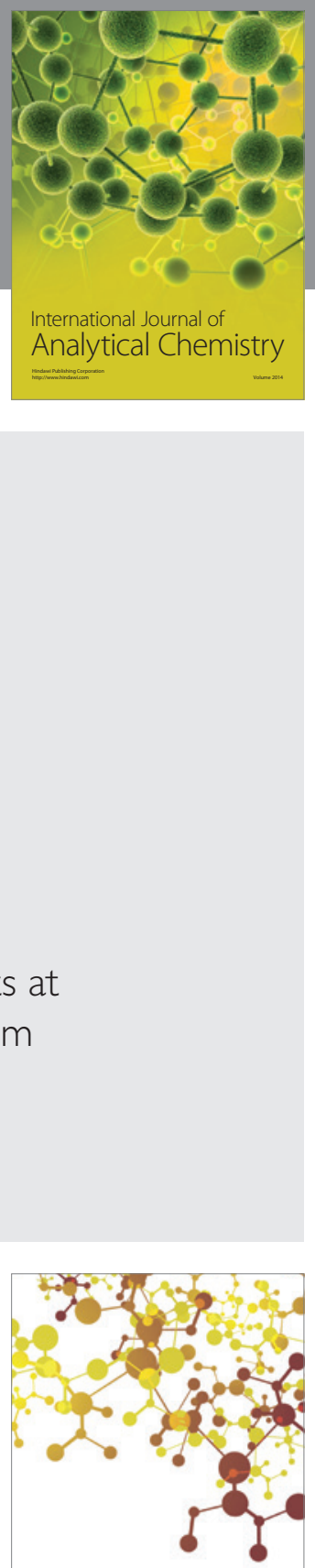

Journal of

Applied Chemistry
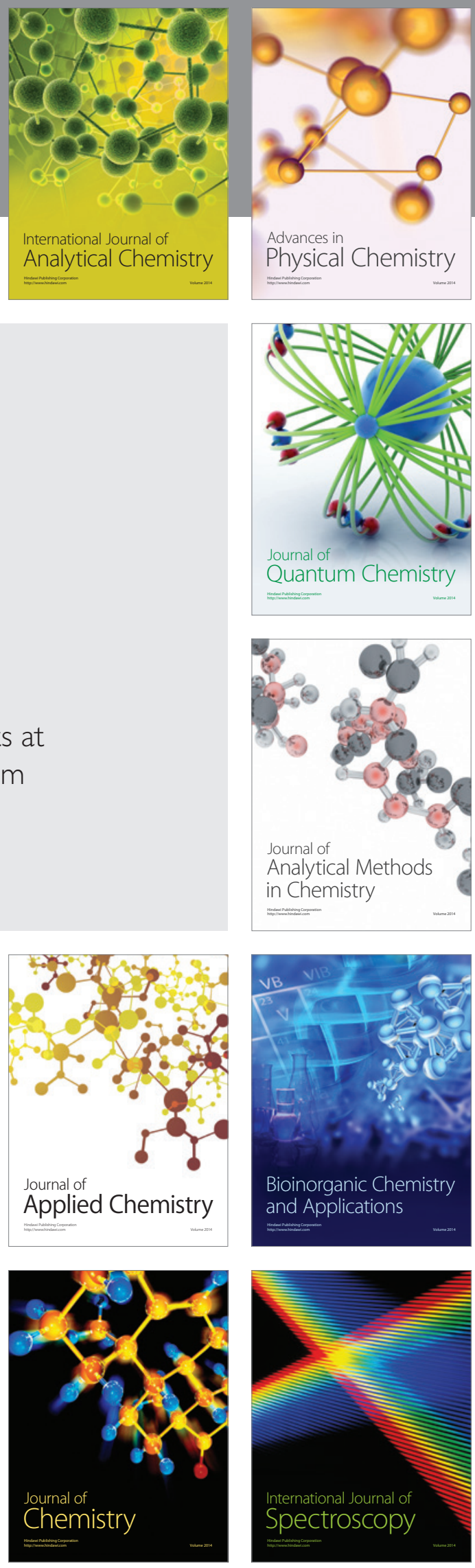